\title{
MODULAR PRINCIPLE TO PRODUCE ACTIVE PROSTHETIC HAND
}

\author{
Anton Kruglov $^{1,2^{*}}$, Gregory Lein ${ }^{1}$, Igor Shvedovchenko ${ }^{2}$ \\ ${ }^{1}$ Scoliologic.ru, Saint-Petersburg, Russia. \\ ${ }^{2}$ Federal Scientific Center of Rehabilitation of the Disabled named after G.A. Albrecht, Saint-Petersburg, Russia. \\ *Email: kruglov@ scoliologic.ru
}

DOI: https://doi.org/10.33137/cpoj.v1i2.32026

\section{INTRODUCTION}

We analyzed the functional prostheses including body powered prosthesis $^{1}$ produced for partial hand amputation. There are almost no solutions on the world market for patients with partial hand amputation. There is no final solution for stump socket (inner socket) that could present both comfort for the stump and cosmetic look of the socket, and at the same time had partial possibility to take the load and transfer it to the power unit. $^{2,3}$

\section{METHODS}

The active hand prosthesis from our develop group was tested with a cohort of 45 patients - 40 male and 5 female, aged 17-55 year old. We carried out questioning within 3 time intervals - prior to supplying, immediately after initial instructing, and after 6 months of using the prosthesis. We used universal questionnaire for assessing the residual hand function DASH. Besides, we used a bench test, evaluating it by the score system before the prosthetics and after teaching how to use the prosthesis. All the patients with partial hand amputation were divided into groups 1.1 and 1.2. The 1.1 group was for patients with partial hand amputation at the level from second line of wrist bones to exarticulation in metacarpophalangeal joint. The 1.2 group - patients with fingers amputation distal from heads of proximal phalanx (Figure 1).

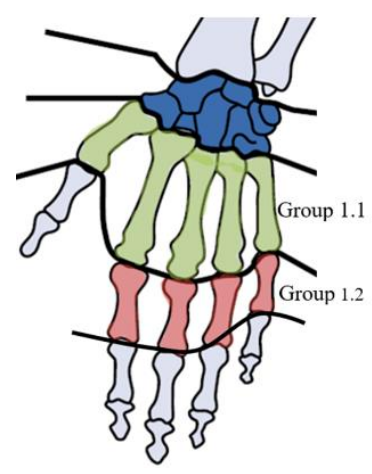

Figure 1. Diagram of levels of amputations groups.
Before recommendation of active hand prosthesis for patients with above named defects the evaluation of wrist's function was made (the moving angle should be no less than 30 degrees), as well as of palm and fingers flexing muscles' force, as the grasp strength of artificial prosthesis fingers is directly proportional to this force.

\section{RESULTS}

The results obtained were statistically significant $(p \leq 0,01)$ (Figure 2, 3). The positive dynamics expressed by patients of group 1.1, revealed by 2 nd questioning and preserved after 6 months of using the prosthesis indicates efficiency of using with active hand prosthesis of presented construction by patients from group 1.1. Thus, indications for this prosthesis should be considered more than $50 \%$ loss of the hand functions due to amputation distal to the metacarpal joints, but proximal to the metacarpalphalangeal joints, including oblique amputation of the hand with loss of more than 3 fingers. The lack of positive dynamics in groups 1.2 and 2.2 is associated with high level of residual hand function in this category, which is reflected in the data of both the bench test and the questionnaire.

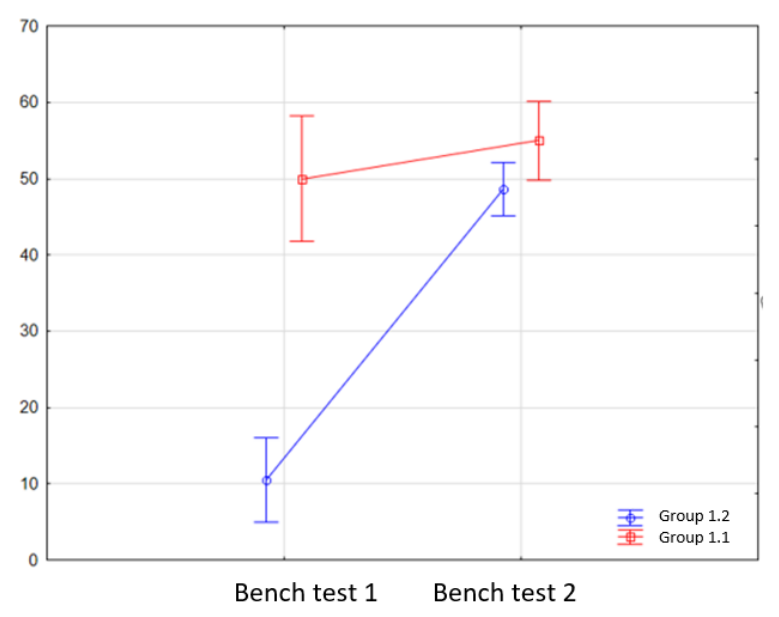

Figure 2. Bench test results. 


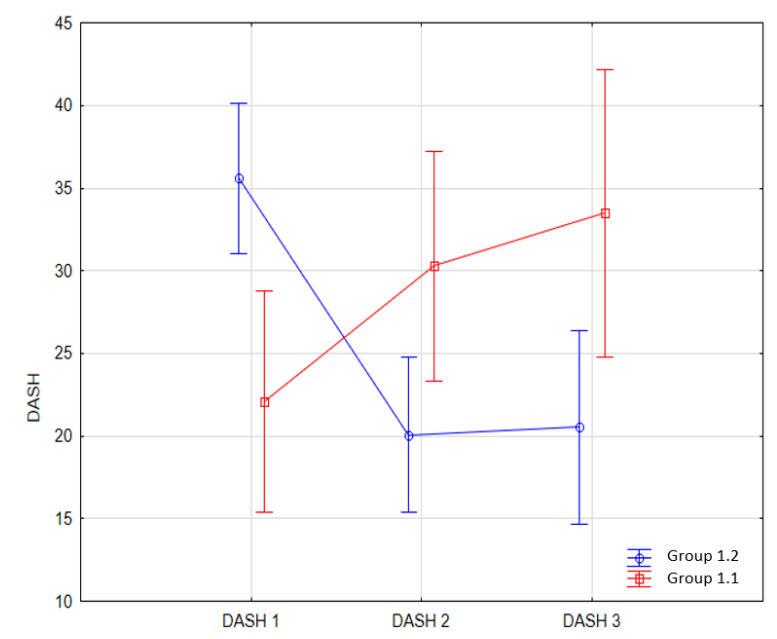

Figure 3. DASH results.

So, contraindications for the active hand prosthesis of the presented design should be considered amputation at the fingers level, from the proximal phalanx and distally.

\section{CONCLUSION}

The presented modular prefab system showed its versatility and stably positive result of prosthetics for patients with various partial hand amputations.

\section{ACKNOWLEDGEMENT}

This research and design work was carried out in the framework of the dissertation research in the Federal Scientific Center of Rehabilitation of the Disabled named after G.A. Albrecht under the guidance of Prof. I.V. Shvedovchenko, with the direct financial participation of "Scoliologic.ru" L.L.C. and personally G.A. Lein.

\section{REFERENCES}

1.Kruglov A.V., Shvedovchenko I.V. Current state of functional prosthetic application in disabled persons with hand and finger stumps // Genij Ortopedii Tom 23, No 3, 2017. DOI: 10.18019/1028-4427-2017-23-3-368-373

2. Schäfer M., Dreher D., Muders F., Kunz S. Prosthetic Fitting after Finger and Hand Amputations // Special print from Orthopädie technik 8/2014 - published by verlag Orthopädietechnik, Dortmund.

3. Schulz S. First experiences with the Vincent hand // "MEC 11 Raising the Standard," Proceedings of the 2011 MyoElectric Controls/Powered Prosthetics Symposium Fredericton, New Brunswick, Canada: August 14-19, 2011. Copyright University of New Brunswick. 